\title{
Editorial
}

\section{Reinvention: Building a future from our past}

I would like to welcome you to this new issue of Reinvention: An International Journal of Undergraduate Research, volume 13, issue 1 (13.1), produced under the strangest of circumstances during the Covid-19 pandemic. We hope all of our readers are keeping safe and well. We are thankful to have been able to continue the production of the issue, despite these circumstances and limitations of the lockdown, and we are lucky to bring you this work from the comfort of our homes to yours.

In these challenging times, society has collectively engaged with the past and future. Many of us have been looking back at past pandemics and times of crisis, or at memories with loved ones. Others have been looking back at core traditions and values, reassessing what is important in their lives. At the same time, we are looking into the future. Questions are being raised relating to how we will choose to move forwards after this crisis and pondering on the various aspects of life that are begging to be re-examined - from personal lifestyles to global politics.

Although the papers and reviews in this issue were written before the pandemic began, their engagement with these questions about the past and future is undeniable, reflecting a larger concern of our times. From looking into gender disparity in politics and re-evaluating medical practices to assessing relationships to future generations and rewriting history, this issue confronts subjects of the past in new ways and invites you to think about the potential impacts on or opportunities created for the future. This theme is also reflected in the way Reinvention is set up, particularly the support network formulated through the review process. As an undergraduate research journal, we ask for more detailed feedback than our academic peer reviewers might typically provide, allowing our authors to expand their knowledge and take their research to the highest standard. Our book reviews, each written by a student and by an academic, also offer the student a chance to write collaboratively with an academic in the field of the book. This enhances the idea of intergenerational unity and allows for established academics to demonstrate their support for the future generation of researchers. Mary Dass has perfectly reflected these ideas in her concept of the intertwining of hands from different generations for the cover of this issue. 
Reinvention: an International Journal of Undergraduate Research 13:1 (2020)

These ideas link to our discussions about Reinvention itself as we too are always looking into the past, reflecting on our core aims and values as a journal, but also into the future as we seek out new ways of development. Once again, this year we have gone back to the idea of accessibility, discussing its importance in the context of the future of research. For this issue, we have introduced a new way of promoting this the introduction of glossaries - hoping to encourage an interdisciplinary readership that we, in turn, anticipate will contribute to more innovative research. At the same time, we are looking forwards and developing the breadth of our content, this time by expanding our current set of reviews to include exhibition reviews, which you will find in this issue.

Edition 13.1 brings you five original research papers, two sets of book reviews and two exhibition reviews. We hope that as you read this work, you will learn something new but also see the positivity the future holds, even in such troubling times.

Ptolemy Banks’s paper 'Myriad-briefing: A pilot study into its effect on participation and its appropriateness for online research' is an exploration of a novel approach to briefing participants in research studies. It is a rigorous examination of the issues created by existing briefing methods and a guide to an entirely new one. The paper is a perfect demonstration of this year's theme and an important piece of work for future studies in various fields.

Avery Beam's ‘Women’s Representation in the Post-Soviet Space: Latvia and Lithuania' dives into the poignant issue of representation through a comparative study of the role of electoral systems in government in Latvia and Lithuania. Beam demonstrates great articulacy in discussing the nature of post-Soviet spaces and is insightful in her investigation of promoting progress.

Amos Ochieng Okutse's ‘The Impact of Sleeping Duration on the Risk of Breast Cancer: A systematic review and meta-analysis of population-based cohort studies' is a detailed analysis of existing literature and studies on the link between sleep and breast cancer. By systematically bringing together this research, the author demonstrates their novel insight, which is significant not only for the medical community but also the general public.

Isa Hassan and Leda Mirbahai’s 'The Role of the Autophagy Inducer Spermidine in Cardiovascular Ageing' is also a work that brings together previous research and literature, this time as an intricate review of spermidine. Through this review, the 

authors demonstrate a key element of undergraduate research by applying a novel perspective onto existing sources, bringing them together to say something new.

The final paper is Lieke Voorintholt's 'Discounting Beyond Death: An exploration of intergenerational distribution preferences'. This paper summarises our theme for the issue by making us think about how we value the welfare of future generations. Voorintholt looks at an apt issue through a novel study, examining the views different generations have towards the future as well as older generations' relationships with future ones.

The papers of this issue are directly complemented by our reviews. Katja Laug and Shayla Rance's review of The New Silk Roads by Peter Frankopan is an insightful dive into the differences between this volume and the original publication from 2015, pondering on the changes not just in the text but in the world they describe. Laug is an IAS Fellow and Sessional Tutor in English and Comparative Literary Studies, and Rance is a Politics undergraduate, specialising in International Relations at Monash. This book reflects the aims of the issue, but also of Reinvention more broadly, as the reviewers comment on its outstanding accessibility and ability to break down complex ideas of political economy for a lay reader.

Our second review is of Invisible Women by Caroline Criado Perez, reviewed by Dr Nese Ceren Tosun and Ridmi Dolamulla. The reviews highlight the author's air-tight argument, which leaves readers with no other option but to confront the reality of the incredibly important subject of gender equality. They also praise the book's ability to look beyond the usual suspects to give a fresh slice of hope on dealing with gender inequality through an interdisciplinary approach. Tosun is an interdisciplinary researcher, lecturer and member of the IATL department at Warwick and Dolamulla is a Biomedical Science undergraduate at Monash.

Finally, for the first time, we present you with two exhibition reviews, reviewing Last Supper in Pompeii held at Oxford's Ashmolean Museum in 2019, an exhibition about the ancient city and particularly its relationship with food - an under-represented topic in the discussion of the city's history. The two reviews were written collaboratively by students in the department of Classics and Ancient History at the University of Warwick. They wonderfully capture the artefacts and presentation of the exhibition as well as critiquing and providing insight into its curatorial choices, while reflecting collaboration advocated by Reinvention. 
In our last issue, former Reinvention editor Hannah Duffus outlined some advice for those thinking of submitting their research to us. She emphasised interdisciplinarity and accessibility. To this I would like to add the elements we have focused on in this issue - specifically the engagement with past concepts and literature, facilitating the ability to see them through a novel perspective, but also thinking about research in terms of its future implementations.

I would like to thank everyone who contributed to this issue and persevered to bring everything together, despite the challenges we are all currently facing in our daily lives. I hope this issue inspires undergraduates to pursue their research and gives optimism about the future to all our readers. We ourselves are looking forward to new collaborations for our next issue as we continue to develop and grow.

To cite this paper please use the following details: Zelmanova, P. (2020), 'Reinvention: Building a future from our past', Reinvention: an International Journal of Undergraduate Research, Volume 13, Issue 1, https://reinventionjournal.org/article/view/631. Date accessed [insert date]. If you cite this article or use it in any teaching or other related activities please let us know by emailing us at Reinventionjournal@warwick.ac.uk. 